\title{
Diel activity cycles of freshwater gastropods under natural light: Patterns and ecological implications
}

\author{
Paola Lombardo*, Francesco Paolo Miccoli, Marco Giustini and Bruno Cicolani \\ Department of Environmental Sciences - Ecology Section, University of L'Aquila, Coppito Science Center, via Vetoio 20, Coppito, \\ 67100 L'Aquila, Italy
}

Received 1st October 2009; Accepted 10 January 2010

\begin{abstract}
Though much is known about freshwater snail ecology, their circadian rhythms remain poorly investigated. Well-fed, stress-free, mid-size adults of six species common in central Italian lakes were exposed to natural sunlight and photoperiod, and their activity status was recorded at 3-h intervals during a 9-d indoor experiment. All species exhibited evident diurnal habits despite high individual variability, with middayto-early-afternoon activity peaks. Activity was correlated with diel light conditions but not with short-term changes in albedo. The prosobranch Bithynia (=Codiella) leachii and the pulmonates Physa (=Physella) acuta and Planorbis planorbis were the most active species and exhibited the longest-lasting response to daytime food addition. The prosobranch Valvata piscinalis exhibited long periods retracted in its shell with the operculum shut, and the remaining taxa (the pulmonates Galba (= Lymnaea) truncatula and Radix (=Lymnaea) auricularia) exhibited an intermediate degree of activity. P. acuta was the most active species at night and exhibited the quicker response to nighttime food addition. Alertedness to (diurnal) predators may be highest for the highly active $P$. acuta and $P$. planorbis, whose antipredator defenses are mainly behavioral. Diel activity patterns and other ecological characteristics suggest that $P$. acuta may be favored in food-rich habitats, while $V$. piscinalis may not be able to fully exploit food resources, especially if in limiting quantities. All snail species - and $P$. acuta in particular - may stimulate periphyton metabolism while keeping its biomass low by grazing mainly during the time of maximum photosynthesis.
\end{abstract}

Key words: Circadian rhythms / light irradiance / feeding behavior / herbivory / predation

\section{Introduction}

Gastropods are common inhabitants of shallow-water habitats such as lake littoral zones (Jokinen, 1987; Brown, 2001). Freshwater snails are typically herbivores, feeding on periphyton, epiphyton on macrophytes, detritus of plant origin, and occasionally on living macrophyte tissue and decaying fragments of dead invertebrates (Brown, 2001; Lombardo and Cooke, 2002).

Snails can be formidable grazers, continuously "cleaning" the substratum with their radula (Bourassa and Cattaneo, 1998; Muñoz et al., 2000). Physids in particular are capable of exerting top-down control of epi/periphyton even in the presence of strong bottom-up forces (high nutrient concentrations: Jones et al., 1999; Lombardo, 2001). High grazing rates suggest that snails may play a major role in shallow-water habitats, maintaining or promoting high water clarity in eutrophic waters by

\footnotetext{
*Corresponding author: physa@tiscali.it
}

enhancing macrophyte well-being through continuous removal of competing epiphyton (Brönmark and Weisner, 1992; Lombardo, 2005). Snail effects on macrophyte productivity may be highest during daylight, when photosynthetic response is highest. However, studies on snail grazing have typically assessed the effects in toto, without separating grazing effectiveness or periphyton/ macrophyte response in daylight or darkness.

Littoral snails also are typically part of rich and diverse macroinvertebrate communities, which include predators (e.g., Macan, 1977; Lombardo, 2005). Predation on freshwater snails by a number of predators was observed or inferred under controlled conditions (Brönmark and Malmqvist, 1986; Kesler and Munns, 1989; Tripet and Perrin, 1994). However, natural populations of snails tend to co-occur at high density with most of their predators (Macan, 1977; Lombardo, 2005).

Broad-reaching investigations suggest that factors typically absent in narrowly focused laboratory settings 
Table 1. Descriptive characteristics and shell size at $t_{0}$ of the six species of gastropods investigated, listed alphabetically. Shell size was taken as diameter for P. planorbis, and as height for all other species ( $n=12$ for all).

\begin{tabular}{llr}
\hline Species & \multicolumn{1}{c}{ Subclass: family } & Shell size at $\mathrm{t}_{0}$ (avg \pm std. err., in mm) \\
\hline Bithynia (=Codiella) leachii Sheppard 1823 & Prosobranchia: Bithyniidae & $6.8 \pm 0.2$ \\
Galba (= Lymnaea) truncatula O.F. Müller 1774 & Pulmonata: Lymnaeidae & $19.4 \pm 0.9$ \\
Physa (= Physella) acuta Draparnaud 1805 & Pulmonata: Physidae & $11.0 \pm 0.7$ \\
Planorbis planorbis L. 1758 & Pulmonata: Planorbidae & $8.8 \pm 0.2$ \\
Radix (= Lymnaea) auricularia L. 1758 & Pulmonata: Lymnaeidae & $17.4 \pm 0.9$ \\
Valvata piscinalis O.F. Müller 1774 & Prosobranchia: Valvatidae & $4.7 \pm 0.2$ \\
\hline
\end{tabular}

may mitigate the potential devastating effects of predators on snails at the community level. For example, some snails are capable of rapid changes in their life histories or shell shape or thickness to minimize predatory losses (Crowl and Covich, 1990; DeWitt et al., 2000; Lakowitz et al., 2008). Using a simplified littoral food web, Lombardo (1997) found that, despite some losses, snails increased in relative abundance thanks to preferential damselfly predation on other prey. Macan (1977) partly explained the conundrum of natural high-density snail-planaria assemblages with planarian low predatory efficiency coupled with high ability to withstand long periods of starvation.

However, other factors potentially contributing to the seemingly stable natural snail-predator coexistence remain largely unexplored. Though recognized - along with food and space - as one of the major niche dimensions (e.g., Pianka, 1976), time remains inexplicably underexplored as a factor potentially separating naturally cooccurring species by means of temporal partitioning of the habitat, or by diel differences in behavior. While some information on temporal habits is available for predators (e.g., Brönmark and Malmqvist, 1986), very little is known about snail diel behavioral patterns that may influence the outcome of predator-snail interactions.

Though circadian rhythms may be disrupted by stress (e.g., McDonald, 1973), the few studies on freshwater snail behavior suggest distinct diurnal, nocturnal, or dawn/ crepuscolar habits (Beeston and Morgan, 1977; Morgan and Last, 1982; Pimentel-Souza et al., 1984; Rotenberg et al., 1989; see also the review in Dillon, 2000). However, such studies have employed artificial light conditions and/ or have focused on economically important species (e.g., intermediate hosts of human parasites). We have determined diel activity patterns for six species of freshwater gastropods common in lake littoral habitats of central Italy, under stress-free, natural-light conditions. The purpose of the investigation was to establish if these species have inherent diurnal or nocturnal habits, and if they partition daily activity temporally.

\section{Materials and methods}

\section{Study organisms}

The six species of gastropods investigated (Table 1) are common in hardwater, permanent lakes throughout Italy and have a pan-European distribution (Girod et al., 1980;
Bank, 2007). The four pulmonate species are thin-shelled, while the two prosobranchs have a sturdier, thicker shell. All species, except Bithynia (=Codiella) leachii, are hermaphroditic. Sexual dimorphism for B. leachii is not apparent. Except for Valvata piscinalis which is negatively affected by water temperatures above $\sim 23-25^{\circ} \mathrm{C}$ (Burgmer et al., 2007; Mouthon and Daufresne, 2008), all species are adapted to warm (temperature $\sim 25-32^{\circ} \mathrm{C}$ ), relatively oxygen-poor, and/or eutrophic waters (Berg and Ockelmann, 1959; Girod et al., 1980; Costil, 1994; Ferreri, 1995; authors' personal observations). All species are herbivorous on periphyton and/or detritus (Brown, 2001; Lombardo and Cooke, 2002; Mouthon and Daufresne, 2008); bithyniids and valvatiids may also filter-feed on suspended particles (Kabat and Hershler, 1993; Mouthon and Daufresne, 2008). Nomenclature follows Dillon et al. (2002) for Physa (= Physella) acuta and Bank (2007) for all other species.

Experimental snails were randomly picked from longterm laboratory cultures comprising the descendants of individuals originally collected in Lake Ventina ( $P$. acuta) or nearby Lake Piediluco (all other species) $\left(42^{\circ} 32^{\prime} \mathrm{N}\right.$, $12^{\circ} 44^{\prime} \mathrm{E}$; WGS 84 coordinates) starting from October 2007. The two source lakes are hardwater, mesoeutrophic, seemingly hydrologically connected, and are located in central Italy within the River Tiber watershed (Gaino et al., 2001). Snails naturally co-occurred with invertebrate predators such as leeches and/or dugesiid planarias (Gaino et al., 2001; authors' personal observation). Snails were reared at the Department of Environmental Sciences of the University of L'Aquila in shallow-water, predator- and parasite-free containers with lake water, periphyton-covered coarse-gravel substratum, and macrophyte fragments, all coming from the source lakes. Material from different lakes was kept in separate aquaria. The original lake water in parent aquaria was gradually diluted and eventually replaced with tap water over several weeks. Experimental snails hatched from intact egg clutches that were transferred into clean, tapwater aquaria before hatching to obtain parasite-free and predator-naïve individuals (Dr. Elżbieta Żbikowska, Mikolai Kopernikus University of Toruń, PL, personal communication). Water was replaced weekly to bimonthly to avoid accumulation of toxins, pheromones, or bacteria that may have caused stress and altered snail biology and behavior (e.g., Chaudry and Morgan, 1987). Cultured snails were fed ad libitum with natural epi/periphyton and decaying plant fragments, integrated with commercially 
Table 2. The four modes used to categorize snail activity, listed from most inactive (top) to most active (bottom). Snails were considered inactive when observed as either inact- or inact + , and active when observed as either act- or act + .

\begin{tabular}{|c|c|}
\hline Activity mode & Description \\
\hline inact- & $\begin{array}{l}\text { Absence of any perceived movement and body completely withdrawn into shell with operculum closed shut } \\
\text { (prosobranchs), or shell aperture closely adhering to the substratum (pulmonates) }\end{array}$ \\
\hline inact+ & $\begin{array}{l}\text { Absence of any perceived movement, but body not completely withdrawn into shell (head and tentacles partly } \\
\text { visible from above); snail apparently "sleeping" or resting, sometimes with production of feces ("digestion") }\end{array}$ \\
\hline act- & $\begin{array}{l}\text { Snail in some perceived movement as "act }+ \text { " (described below), but at a markedly lower degree } \\
\text { of movement/activity }\end{array}$ \\
\hline act + & $\begin{array}{l}\text { Very evident movement (roaming; sliding upside down at the water surface; crawling above water level); } \\
\text { active foraging/scavenging with or without locomotion (radular/tentacle movement); oviposition }\end{array}$ \\
\hline
\end{tabular}

available lettuce and 5\%-Spirulina-enriched flake food for aquarium fish to supplement proteins and vitamins. Laboratory-reared snails adapted quickly to fish food, and became able to detect and consume flakes within minutes from addition. Rearing aquaria were placed near a large window facing $\mathrm{W}$, whose adjustable blinds were regulated daily to avoid exposure to direct sunlight and to minimize fluctuations in temperature, which otherwise followed seasonal trends. Cultured snails remained thus exposed to natural daylight and photoperiod since hatching. Species-specific general behavior of laboratory-reared snails did not change appreciably in time, or from fieldcollected parent individuals. Mortality in all aquaria remained very low through the experiment period.

\section{Experimental setup}

The experiment was carried out in an indoor locale in suburban Rome, Italy $\left(41^{\circ} 43^{\prime} \mathrm{N}, 12^{\circ} 21^{\prime} \mathrm{E}\right)$. A subsample of several individuals was moved from L'Aquila to Rome in early March to acclimatize to the ambient conditions of the experimental locale. Water temperature, tap water quality, natural photoperiod and irradiance, westerly exposure to natural sunlight, and quantity and quality of food provided were similar in the long-term culturing locale in L'Aquila and in the pre- and experimental locale in Rome. Fifteen-to-eighteen adult individuals of each snail species were randomly picked up from the Rome subsample aquaria $24 \mathrm{~h}$ before the beginning of the experiment, transferred into a small container with $\sim 1 \mathrm{~L}$ of tap water, and transported to the experimental locale, where they were left to reach ambient temperature overnight in moonlit, natural darkness. Snails were fed a mixture of lettuce leaves, periphyton, and commercial fish flake food ad libitum.

The next morning, 72 glass jars were each filled with $125 \mathrm{~mL}$ of tap water and placed in 6 rows $\times 12$ columns on a white-surface desk alongside a large unobstructed window facing WNW. Jars received diffuse natural daylight from dawn through dusk. Midday light irradiance at the jar water surface was $\sim 70-120 \mu$ mol.m ${ }^{-2} . \mathrm{s}^{-1}$, simulating natural conditions in vegetated lake littoral zones at $\sim 1 \mathrm{~m}$ of depth (P. Lombardo, unpublished data). Jars had been analytically cleaned before use with a $10 \% \mathrm{HCl}$ solution, followed by thorough rinsing with tap water, to eliminate preexisting chemical cues that may have influenced snail behavior. Tap water in the jars was left undisturbed for $\sim 14 \mathrm{~h}$ to lose excess chlorine and reach an equilibrium with ambient temperature. Snails were starved during this period. Water temperature in jars and in the snail-containing aquarium reached an equilibrium at $\sim 19.6^{\circ} \mathrm{C}$ at $\sim 22: 00$.

At this time, twelve mid-size adults of each snail species (regardless of sex for B. leachii) were randomly picked from the transporting container and placed in the experimental jars following a modified Latin-square layout, in which each six-jar column (perpendicular to the window) was assigned randomly within each of two contiguous Latin squares, so that each square of $6 \times 6$ jars featured one individual of each taxon per row and per column. Such a design allowed to equally distribute any small between-row difference in light irradiance among the six snail species. Each jar received one snail individual, which was initially placed at the jar center to standardize initial conditions. The remaining snails were left in the transporting container near the experimental jars, to monitor snail well-being and behavior under parallel, non-experimental conditions.

The activity of each snail individual was recorded following the scheme in Table 2 every $3 \mathrm{~h}$ starting from 0:00 (midnight) on 16 March (i.e., $\sim 2 \mathrm{~h}$ after snail addition to jars) through 24 March 2009, spanning nine consecutive 24-h cycles. The degree of activity (act- and act+) was relative to each species, so that individuals of species naturally more active sensu latu (e.g., B. leachii, $P$. acuta) were proportionately more active than individuals for other species in the same activity mode; for example, act $+P$. acuta individuals were, on average, more active (e.g., mobile) than act $+V$. piscinalis individuals. Inactivity was defined as absence of any detectable body movement (including tentacle or radular movements) during $10-20 \mathrm{~s}$ of close visual inspection. Preliminary inspections lasting $>30-40 \mathrm{~s}$, especially at night, appeared to startle and "wake up" inactive snails and were avoided. Nighttime observations were made with the help of a small flashlight covered with a dark-red semitransparent plastic filter to minimize disturbance (Peckarsky and Cowan, 1995; Tomba et al., 2001). Records for individuals which died during the 9-d investigation were excluded since 
3-6 observation rounds before death; such individuals were thus maintained as replicates, but their activity data were averaged over a lower number of daily cycles.

Shell size of each snail individual was recorded at the beginning $\left(\mathrm{t}_{0}\right)$ and end $\left(\mathrm{t}_{\mathrm{F}}\right)$ of the investigation with an electronic precision caliper (instrument error $=0.01 \mathrm{~mm}$ ). Shell size was determined as shell diameter for Planorbis planorbis, and as shell height for all other species. The number of egg masses produced by each individual was recorded at $t_{F}$. Surviving snails were returned to the culturing aquaria at the end of the experiment.

Each 3-h round of observations began with recording snail activity, avoiding any physical contact with the jars and direct flashlight beam (at night) on individual snails to prevent any influence on behavior, followed by determinations of water temperature and $\mathrm{pH}$, and light irradiance at the jar water surface. In the few cases when indirect-beam flashlight was insufficient to discern snail behavioral mode reliably, the beam was oriented away from yet-to-beobserved individuals, and the activity mode observed in the first 2-4 s was recorded: inactive snails disturbed by a direct flashlight beam in preliminary trials appeared to "wake up" after 4-5 s; snails active at night did not change their behavior appreciably for the first 15-20 s after being hit by direct flashlight beam.

Physicochemical variables were determined with electronic equipment at one randomly chosen jar for each of three subblocks of contiguous jars (4 window-parallel rows $\times 6$ columns). Water temperature was determined with a NIST-calibrated Traceable $^{\circledR}$ minithermometer (instrument error $=1{ }^{\circ} \mathrm{C}$ ), and $\mathrm{pH}$ was determined with a handheld $\mathrm{pH}$-meter calibrated at circumneutral values at $20^{\circ} \mathrm{C}$ (instrument error $=0.1 \mathrm{pH}$ units). The small submergible probes minimized physical disturbance during reading. Water temperature and $\mathrm{pH}$ remained within the relatively narrow ranges of $\sim 16-20^{\circ} \mathrm{C}$ and $7.9-8.3$ units, respectively. Such ranges are unlikely to influence the biology of any of the snail species investigated (Hodasi, 1976; Girod et al., 1980; Costil, 1994; Mouthon and Daufresne, 2008; and authors' personal observations); therefore, water temperature and $\mathrm{pH}$ are not treated further in this study.

Light irradiance was determined with a sunlightcalibrated aerial quantum meter (instrument error $<1 \%$ ), measuring photosynthetically active radiation (PAR). The light meter was held just above the jars at $\sim 45^{\circ}$ facing the window. Light:dark conditions followed the natural daylight cycle, around spring equinox $(\mathrm{D}: \mathrm{L}$ $\sim 12: 12 \mathrm{~h}$ ). The 6:00 and the 18:00 observation rounds corresponded to dawn and dusk conditions, respectively. Each complete round of observations and measurements was carried out in $\sim 12-15$ minutes.

Food was added at regular $36-\mathrm{h}$ intervals since $0: 30$ on day- $1\left(\mathrm{~d}_{1}=\mathrm{t}_{0}\right)$. The 36 -h interval allowed to have three alternating daytime and nighttime food additions, thus avoiding food-induced bias in diel activity patterns. Food consisted of a mixture of periphyton and fish food in flakes. The quantity of food added at each event was designed to allow leisurely feeding for the first $\sim 24 \mathrm{~h}$ and

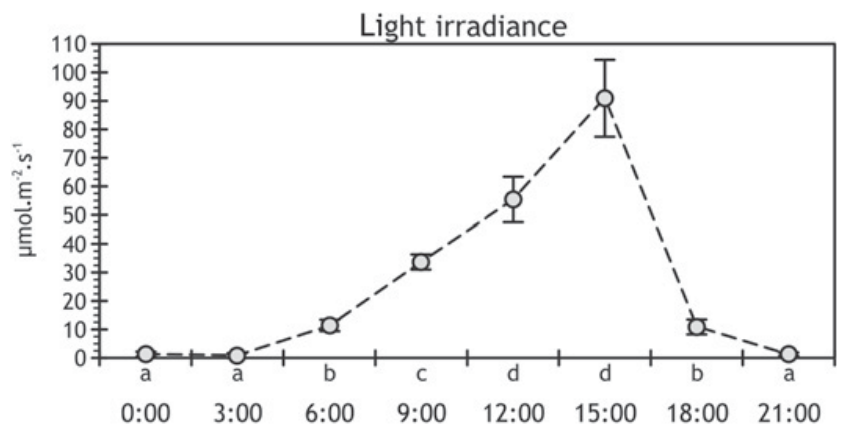

Fig. 1. Light irradiance during the 24-h observation cycles, with observations carried out every $3 \mathrm{~h}$ starting at midnight (average \pm standard error; $n=9$ for each time period). Lowercase letters identify different average values according to an SNK test $(p \leq 0.05)$ performed after a significant one-way, type I ANOVA on log-transformed data $(F=103.175, d f=7,64$, $p<0.001)$.

a brief 12 -h period of starvation comparable for all species, and was thus tailored to each species based on preliminary trials. The 12 -h starvation period was designed to avoid excess leftover that may have led to bacterial development in the jars, and to mildly stimulate snail response to the next feeding event, based on information in Ter Maat et al. (2007). Response to food inputs was determined as changes in activity at 15 -min intervals from just before food addition (at 12:30 or $0: 30$ ) through the next scheduled observation round. Foodaddition events were started $30 \mathrm{~min}$ after a regular observation round because snails were observed regaining their original activity mode within $10-20 \mathrm{~min}$ from mild disturbance in preliminary trials; the 30 -min hiatus therefore allowed to have undisturbed snails at the first (pre-feeding) observation event. Individual snails were recorded only as active or inactive during the foodresponse observations to allow faster inspection rounds ( $\sim 10 \mathrm{~min}$ each). Food addition did not cause appreciable alterations in $\mathrm{pH}$.

\section{Statistical analysis}

Analysis was based on the times of occurrences in any given mode of each snail individual averaged over the 9-d experimental duration. The single value per individual obtained this way was thus a true replicate, avoiding the issue of temporal pseudoreplication (sensu Hurlbert, 1984) that may stem from multiple observations on the same individuals. Taxon-specific analysis employed one-way, type I ANOVAs on such true replicates to test for differences among observation times. Such a method is deemed more robust than an otherwise equivalent nested design, in which individual daily observations would be kept as subreplicates (Gotelli and Ellison, 2004). Data were expressed as percent of total number of individuals, so that data transformation was not necessary (Zar, 1998). Significant ANOVAs were followed by 
Table 3. Numerical characteristics of the six gastropod species at $t_{F}$. Shell size is as described in Table 1. For determinations of average values, $n$ is given in the column at the left; $\mathrm{nc}=$ not calculable. Number of individuals per species at $\mathrm{t}_{0}$ was 12 .

\begin{tabular}{lcccc}
\hline Species & $\begin{array}{c}\text { Number of surviving } \\
\text { individuals } \\
\text { at } \mathrm{t}_{\mathrm{F}}\end{array}$ & $\begin{array}{c}\text { Increase in shell } \\
\text { size at } \mathrm{t}_{\mathrm{F}} \text { (avg } \pm \text { std. err., } \\
\text { as \% of size at } \mathrm{t}_{0} \text { ) }\end{array}$ & $\begin{array}{c}\text { Number of egg-laying } \\
\text { individuals } \\
\text { by } \mathrm{t}_{\mathrm{F}}\end{array}$ & $\begin{array}{c}\text { Number of egg masses } \\
\text { laid per egg-laying } \\
\text { individual (avg } \pm \text { std. err.) }\end{array}$ \\
\hline B. leachii & 12 & $2.8 \pm 1.4$ & 7 & $2.4 \pm 0.3$ \\
G. truncatula & 12 & $2.3 \pm 0.4$ & 2 & $2.0 \pm 0$ \\
P. acuta & 12 & $1.9 \pm 0.4$ & 11 & $4.7 \pm 0.7$ \\
P. planorbis & 12 & $6.8 \pm 0.5$ & 9 & $3.3 \pm 0.6$ \\
R. auricularia & 9 & $1.5 \pm 0.7$ & 5 & $1.8 \pm 0.4$ \\
V. piscinalis & 12 & $4.8 \pm 1.4$ & 1 & $4.0 \pm \mathrm{nc}$ \\
\hline
\end{tabular}

Student-Newman-Keuls (SNK) multiple-comparison tests with $p \leq 0.05$. Two-tailed paired $t$-tests were used to quantify the degree of activity (act- + act + ) at taxon level; paired tests were used to bypass the potential statistical shortcomings caused by the negatively correlated data (Underwood, 1997).

Species-specific peak activity times were calculated as average angles on angle-transformed hourly data $\left[x^{\prime}=\frac{(360) \cdot x}{24}\right]$ with associated coefficients of angular concentration $\left(r_{\mathrm{c}}\right)$ (Batschelet, 1965, 1981; Zar, 1998); differences were tested with a second-order analysis of angles (Hotelling, 1931) as modified by Lombardo and Cooke (2004). Species-specific daily peak activity times significantly different from the group's average were determined as nonoverlapping peak time \pm pooled standard error (Lombardo and Cooke, 2004). Angular statistics proved unreliable for incomplete-cycle food addition data and were applied only to complete $24-\mathrm{h}$ cycle data. Graphical rendition of diel data remained linear for clarity purposes.

Temporal changes in light irradiance were detected with a one-way, type I ANOVA followed by an SNK test $(p \leq 0.05)$ on log-transformed data (Bartlett's formulation: $\left.x^{\prime}=\log _{10}(x+1)\right)$. Correlations between selected datasets used untransformed data because of analysis reliability when nonnormality is not extreme (Zar, 1998). For correlations, independence of activity data at subsequent 3-h observation times (e.g., 12:00 and 15:00) was assumed based on the much-shorter activity bouts observed for all species in preliminary and experimental trials; feeding events were not used in correlations because of evident autocorrelation between subsequent 15-min-spaced observation times.

\section{Results}

Light irradiance at the water surface exhibited evident day-night cycles, with full statistical separation among the three full-daylight $(9: 00,12: 00$, and $15: 00)$, the three fullnighttime $(21: 00,0: 00$, and $3: 00)$, and the twilight observation rounds (6:00 and 18:00) (Fig. 1). Weather conditions were variable but overall benign; for example, conditions at 15:00 ranged from cloudless or mostly sunny skies (five events) to partly cloudy (three events) to overcast and light rain conditions (one event). All snail species grew slightly and laid eggs, and all but three
R. auricularia individuals survived through the 9-d experiment (Table 3).

All species exhibited the highest degree of activity during daytime (SNK separation in Fig. 2). B. leachii, $P$. acuta, and $P$. planorbis exhibited the highest daytime activity, with $\sim 70-80 \%$ of individuals recorded as active at peak activity times. These species also tended to be significantly active during full daytime (9:00 through 15:00), significantly inactive in full nighttime (21:00 through 3:00), and at an intermediate degree of activity in twilight (6:00 and 18:00) (paired $t$-tests in Fig. 2). All species except $R$. auricularia were significantly active at 12:00 and all were significantly inactive at 3:00 (marginally so for P. acuta). R. auricularia never reached a significant level of activity (paired $t$-tests in Fig. 2).

Pulmonate snails and $B$. leachii were rarely observed fully retracted in their shells (i.e., mode inact-), while the operculate prosobranch $V$. piscinalis spent considerable time in such mode (Fig. 2). Despite the high individual variability, $V$. piscinalis was always observed significantly more frequently in mode inact- than all other species (SNK separation at $p \leq 0.05$ after significant one-way, type I ANOVAs for each time interval, with $F \geq 3.668$ and $p \leq 0.004 ; d f=6,48$ for all). All species were often observed sliding upside down at the water surface (one of the active modes described in Table 2), and all pulmonates were observed crawling above the water surface, often staying there in mode inact + for some time, especially after food additions. Such individuals reentered the water medium shortly thereafter.

Snail activity was significantly, positively correlated with diel light irradiance for all species, though the level of significance was marginal for Galba truncatula (Table 4). However, activity was not correlated with light conditions during the periods of highest irradiance and/or highest degree of activity (12:00 and 15:00).

The six gastropod species collectively exhibited an early-afternoon (12:54) daily peak in activity, but peak activity times differed significantly among the six gastropod species (Hotelling's (1931) second-order analysis of angles: $F=17.588, p=0.011$ ) (Fig. 3). B. leachii, $P$. planorbis and $R$. auricularia shared similar daily peak activity times, while $P$. acuta's peak activity at 14:02 was the most (significantly) distinct from the group average. Coefficients of angular concentration (an inverse measure 

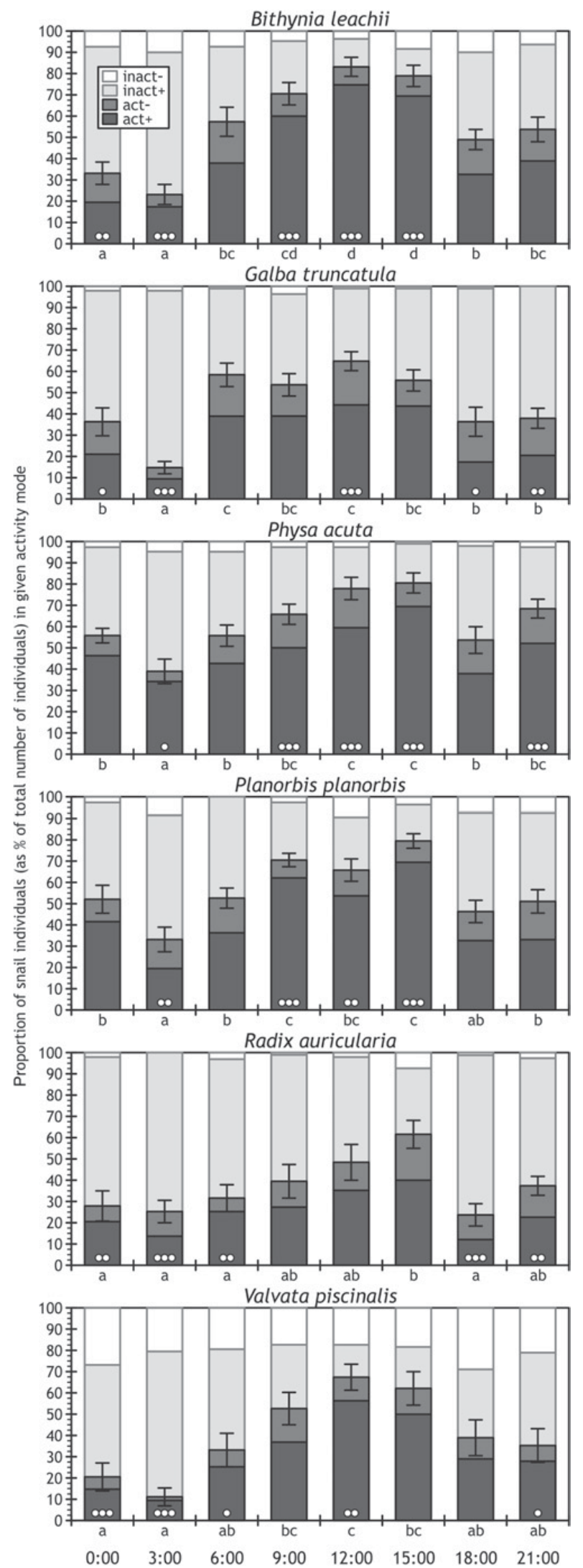

Fig. 2. Average individual activity cycles, as proportion of occurrence in the given mode by 3 -h observation interval, for the six species examined; $n=12$ for each species in each time period. Standard error and statistical analysis are given for total "active" of variability) were low for all species $\left(r_{\mathrm{c}}=0.11-0.31\right.$, Fig. 3).

Daytime food addition was associated with an increase in the level of activity only for $P$. planorbis (SNK separation in Fig. 4). B. leachii and P. acuta maintained a highly significant degree of activity through the daytime food addition event, while $G$. truncatula eventually slowed down to nonsignificant activity levels by the next observation round (paired $t$-tests in Fig. 4). $R$. auricularia exhibited the slowest average response to daytime food addition $\left(\sim 2 \frac{1}{2} \mathrm{~h}\right.$ after food addition, as significant degree of activity from nonsignificant values for the paired $t$-tests in Fig. 4). Nighttime food addition caused an increase in the degree of activity (paired $t$-tests) for all species, either from significantly inactive to nonsignificant (B. leachii, $G$. truncatula, $R$. auricularia, and $V$. piscinalis) or from nonsignificant to significantly active ( $P$. acuta and $P$. planorbis), though the increase was strong only for $G$. truncatula and P. acuta (SNK separation in Fig. 4). $P$. acuta exhibited the quickest response to nighttime food addition (SNK separation after significant ANOVAs at each 15-min time interval; detailed results not shown). Nighttime activity was restored to pre-feeding levels $\sim 1 \frac{1}{2}$ $2 \mathrm{~h}$ after food addition for most species.

Response time of inactive (inact -+ inact + ) snail individuals to food additions varied from $\sim 15$ ( $P$. acuta) to $\sim 165 \min$ ( $V$. piscinalis), but between-species differences remained qualitative (one-way ANOVAs on log-transformed data: $F_{\text {day }}=0.262, p=0.93, d f=5,44$; $\left.F_{\text {night }}=1.231, p=0.31, d f=5,62\right)$, as did species-specific daytime $v s$. nighttime differences (two-tailed $t$-tests performed separately for each species using log-transformed data: $t=0.229-1.010, p=0.33-0.82, d f=14-21)$. However, nighttime response of inactive snails to food addition was significantly slower than daytime response when data were pooled (paired $t$-tests using log-transformed average values for each species: $t=5.342, p=0.003, d f=5$ ). When fully retracted inside their shells with the operculum shut, $B$. leachii and especially $V$. piscinalis seldom responded to food additions within the $2 \frac{1}{2}$-h observation periods, while the individual response of inact- pulmonates was more variable; however, this behavior was not quantified.

\section{Discussion}

Experiment-long shell growth and oviposition (Table 3) recorded for all species suggest that the

mode (=act- and act + ); lower-case letters identify different average values according to SNK tests $(p \leq 0.05)$ performed after significant one-way, type I ANOVAs. Significant differences between proportions of active $(\mathrm{act}-+\mathrm{act}+)$ and inactive occurrences (inact- + inact + ), tested with two-tailed paired $t$-tests, are given at three levels of significance $(\bigcirc=p<0.10$, $\bigcirc \bigcirc=p<0.05$, and $\bigcirc \bigcirc \bigcirc=p<0.01$ ). Activity modes are described in Table 2, and detailed statistical results are in Tables A1 and A2 (Online Material available at www.limnology-journal.org). 
Table 4. Linear regressions between light irradiance and snail activity. For 24-h cycle analysis, average light irradiance was regressed against average activity (as \% of individual occurrences in active mode) for each of the 3-h-spaced observation events $(n=8)$; analysis of the highest light irradiance used daily values at 12:00 and 15:00 $(n=18)$. For all regressions, $d f=n-2$.

\begin{tabular}{|c|c|c|c|c|c|c|}
\hline \multirow[b]{2}{*}{ Species } & \multirow[b]{2}{*}{$r^{2}$} & \multicolumn{2}{|c|}{ Average values, 24 -h cycles } & \multirow[b]{2}{*}{$r^{2}$} & \multicolumn{2}{|c|}{ Daily values, $12: 00$ and $15: 00$} \\
\hline & & $p$ & Trend & & $p$ & Trend \\
\hline B. leachii & 0.661 & 0.01 & + & 0.099 & 0.20 & + \\
\hline G. truncatula & 0.421 & 0.08 & + & 0.111 & 0.18 & - \\
\hline P. acuta & 0.626 & 0.02 & + & 0.103 & 0.19 & + \\
\hline P. planorbis & 0.755 & 0.02 & + & 0.043 & 0.41 & + \\
\hline R. auricularia & 0.902 & $<0.01$ & + & 0.002 & 0.87 & - \\
\hline$V$. piscinalis & 0.714 & 0.01 & + & 0.099 & 0.20 & + \\
\hline
\end{tabular}

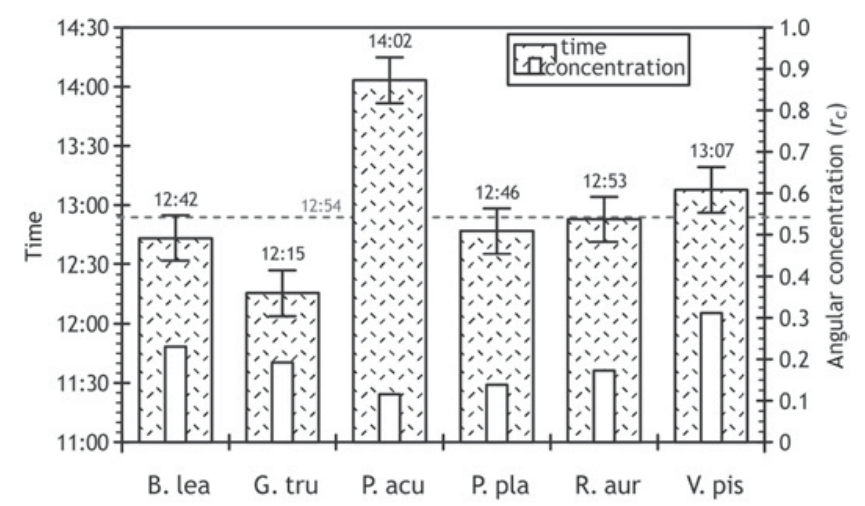

Fig. 3. Daily peak activity times for the six gastropod species, calculated as average angular data \pm pooled standard error (left axis). The angular concentration ( $r_{\mathrm{c}}$, right axis) is a measure of species-specific variability in behavioral activity, ranging from zero (maximum variability) to one (absence of individual variability) (after Zar, 1998). The horizontal dashed grey line identifies the group peak time (12:54) averaged over the six species (as angular grand average of species-specific averages, after Zar, 1998). Daily peak activity times \pm pooled standard error not overlapping with the average group peak time of 12:54 differ significantly from the group average (after Lombardo and Cooke, 2004). Taxa are identified by genus initial followed by the first three letters of the species name; full names are in Table 1.

experimental conditions, including the 36 -h food additions with the deliberate $\sim 12$-h pre-feeding starvation period, were not stressful. Based on qualitative observations in the 1-L "leftover" container and in culturing aquaria, the low degree of oviposition of $G$. truncatula and $V$. piscinalis (Table 3) appeared to be associated with seasonal reproductive cycles. Absence of jerky movements by active snails, rare long-term wandering above the water line by pulmonates, and rare complete withdrawals into shells also indicate minimal or absent stress (Turner et al., 1999; Hourdin et al., 2006; Ms. Sarah Rid, University of Konstanz, personal communication). Short-term crawling just above the water level, with snails voluntarily reentering the jar water by the next observation round, appeared to be most often post-feeding moments of rest, and was not interpreted as a response to stress. Based on general behavior in culturing and leftover aquaria, the sometimes several hours spent by $V$. piscinalis without any movement and fully retracted in their shell (inact- mode) appeared to follow long activity periods (spent mainly foraging), and were similarly not interpreted as a sign of stress. Experiment-wide mortality was limited to three $R$. auricularia individuals, also supporting the interpretation of general absence of stress in the experimental jars. The cause for the three $R$. auricularia deaths remains unknown, as such individuals did not behave unusually or differently from fellow $R$. auricularia individuals until shortly (i.e., for 2-5 observation rounds) before their deaths, and we remain unable to ascertain any cause-effect relationship between the low degree of activity (Fig. 2) and the experiment-related mortality of $R$. auricularia.

All six species exhibited evident diurnal habits (Figs. 2 and 3, Table 4), supporting the view that stress-free freshwater snails follow distinct, species-specific diel or dark-light activity cycles (e.g., Beeston and Morgan, 1977; Pimentel-Souza et al., 1984). Light was proven or inferred as a strong behavioral clue also in earlier investigations (Pimentel-Souza et al., 1984; Rotenberg et al., 1989; Ter Maat et al., 2007). However, absence of a fine-scale correlation between activity and light irradiance during the daily period of highest activity and irradiance (Table 4) suggests that short-term changes in albedo do not influence snail diel cycles. All species also exhibited high individual variability (e.g., low $r_{\mathrm{c}}$ values in Fig. 3), suggesting variability in individual conditions (e.g., hunger) and/or a high degree of phenotypic plasticity, supporting earlier results (Russell-Hunter, 1961; Perrin, 1986; Crowl and Covich, 1990; Lakowitz et al., 2008). Despite high individual variability, all species (except $R$. auricularia) were significantly active for at least one time interval at or around noon (significant paired $t$-tests in Fig. 2).

Independent, qualitative parallel observations in culturing aquaria and in the "leftover" small container suggest that most species feed during daytime through the early evening hours, then rest apparently digesting (production of feces) under or above the water level for a short time, before entering a short-lived "second wind" time of activity around midnight in which they seek sexual mates, eventually entering an apparent "deep sleep" by $\sim 1: 30-2: 00$. Such a qualitative behavioral pattern is reflected in the experimental results of a midday-toafternoon peak in activity (Figs. 2 and 3) followed by a period of "rest" at dusk and/or into the early evening 

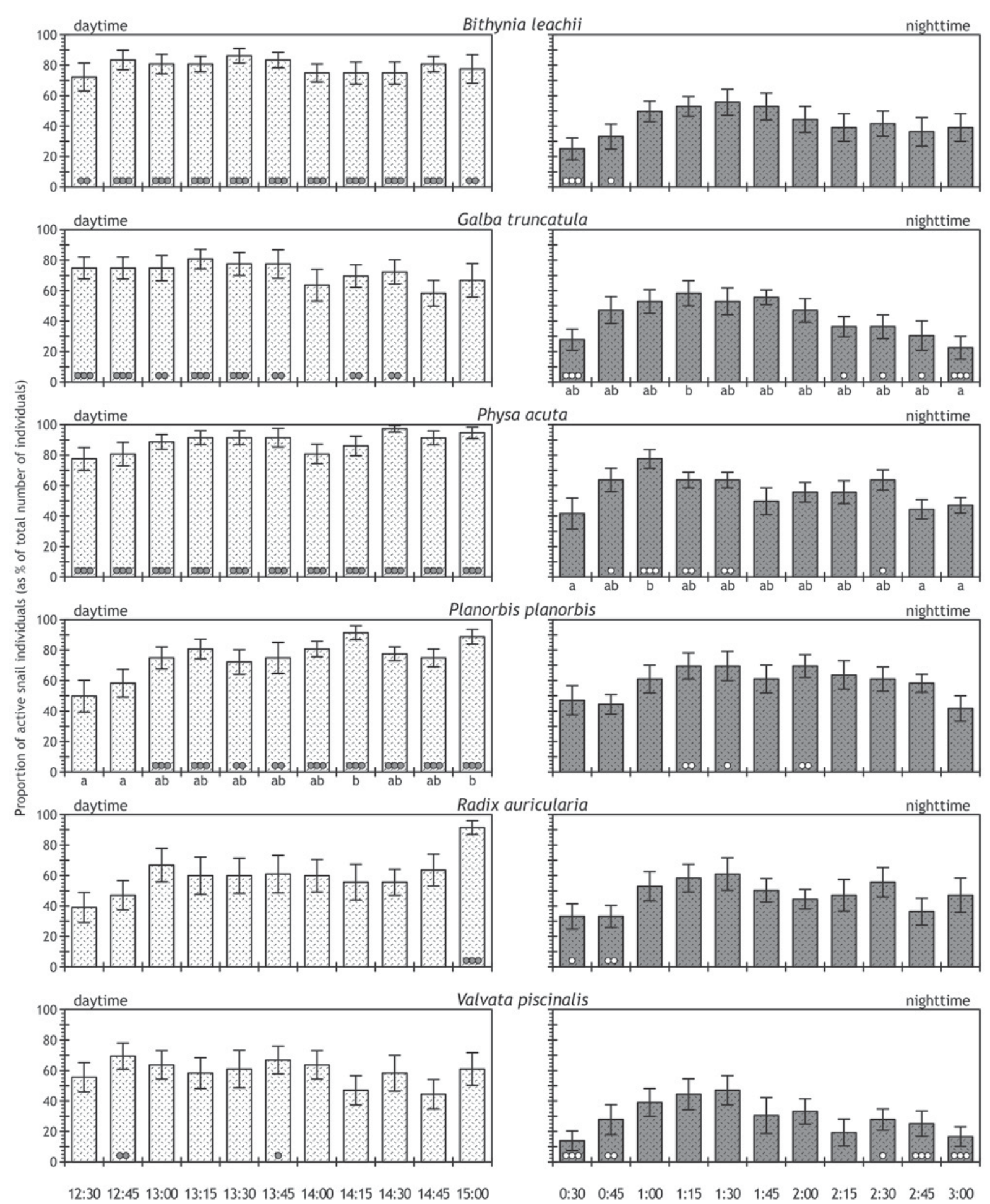

Fig. 4. Occurrence in active mode (as $\%$ of total number of individuals; average \pm standard error) just before (12:30 or $0: 30$ ) and at 15 minute intervals after daytime (left panels) and nighttime food addition (right panels), for the six species examined. Other explanations as in Figure 2; detailed statistical results are in Tables A3 and A4 (Online Material).

hours, followed in turn by a reprise in activity at midnight before entering the quantitative moment of highest diel inactivity at 3:00 (SNK separation in Fig. 2).

Response to daytime food addition remained mostly nonsignificant, either because most species were already highly active just before food addition (B. leachii,
G. truncatula, P. acuta), or because individual response to food addition was highly variable ( $R$. auricularia, $V$. piscinalis), resulting in nonsignificant statistical outcomes ( $t$-tests and/or SNK separation in Fig. 4; between-species SNK separation at $p \leq 0.05$ (not shown)). The species that were most active during daytime 
(B. leachii, P. acuta, and P. planorbis) also remained highly active throughout the $2 \frac{1}{2}$-h daytime food event period (Fig. 4), suggesting that these species may readily take advantage of food, whether the latter is found via active pursuit or provided as pulse inputs (e.g., detritus or macrophyte fragments carried by water currents). $P$. acuta exhibited the quickest and most intense response to nighttime food addition, both as a significant increase in average activity within $15 \mathrm{~min}$ from food addition, and as average number of active individuals $(\sim 78 \%$ of total number of individuals) within $30 \mathrm{~min}$ from addition ( $t$-tests and SNK separation in Fig. 4 and for betweenspecies comparisons; detailed results not shown). General activity patterns and response to food suggests that $P$. acuta may be the most opportunistic species among the six investigated, being capable of quickly exploiting food sources at any time of the day. However, the shortlived and/or mild response to nighttime food addition exhibited by most species (Fig. 4), coupled with the "community-wide" significantly longer nighttime response ( $p=0.004$ for a paired $t$-tests using pooled data), strongly support the general diurnal activity patterns displayed by all species (Figs. 2 and 3).

The activity patterns found in this study may reflect broader species-specific ecological characteristics which, in turn, may be related to community-level features such as interspecific competitive ability. For example, P. acuta is considered a poor competitor (Brown, 1982; Perrin, 1986; Jokinen, 1987) despite its high grazing effectiveness (e.g., Lowe and Hunter, 1988; Lombardo, 2001; but see Wojdak and Mittelbach, 2007) and success in productive habitats at both local/regional (e.g., Girod et al., 1980, and authors' personal observations) and global scale (Dillon et al., 2002). P. acuta's high activity and quick response to food may translate into a high potential to exploit food, which may be exacerbated by its fast way of moving around (thus increasing access to food patches: Lombardo and Cooke, 2004). Similarly, P. acuta's high individual variability and daily activity peak significantly later than all other species (Fig. 3) may alleviate some of the competitive pressure by reducing interference-based interactions with co-occurring snail species. Though the hypothesis remains untested, such features may thus compensate for $P$. acuta's inherent poor competitive ability at least in food-rich (and hence often species-rich; e.g., Jokinen, 1987; Costil and Clement, 1996) gastropod communities, which typically feature abundant physid populations (e.g., Jokinen, 1987; Lombardo, 2005). The high degree of activity also may be behind the apparent replacement of the native Physa fontinalis L. 1758 by the North American P. acuta in much of western and Mediterranean Europe (Anderson, 2003; Cianfanelli et al., 2007; García-Berthou et al., 2007); however, direct comparisons between these two physids are needed to support this hypothesis.

General low diel activity and related behavioral patterns of $V$. piscinalis (e.g., high degree of time spent with the operculum closed shut; short-lived response to nighttime food addition: Figs. 2 and 4) also suggest poor competitive abilities, a hypothesis consistent with Mouthon and Daufresne's (2008) view that this species has failed to recover from acute thermal stress because of high competition for post-disturbance limited food resources. Low in situ abundance of the otherwise common $V$. piscinalis in central Italian lakes (Mastrantuono and Mancinelli, 2005; authors' personal observations), may be similarly related to poor competitive abilities, but specific studies are needed to verify this hypothesis.

Though it spent considerable less time in mode inactthan $V$. piscinalis, B. leachii also exhibited a poor (if any) response to food addition when in such mode, suggesting that the lowered competitive abilities resulting from such an "isolationist" behavior may be a trade-off for an effective antipredator defense. B. leachii's de facto invulnerability to predatory attacks by invasive invertebrate predators such as dugesiid planarias in specifically designed experiments (P. Lombardo, unpublished data) supports this hypothesis ( $V$. piscinalis was not tested), as do earlier findings of a combination of operculum shutting and chemical predator recognition for B. tentaculata and/ or $V$. piscinalis as an effective defense against leech predation (Brönmark and Malmqvist, 1986; Kelly and Cory, 1987). In general, active diurnal species may be more alert against diurnal predators and more vulnerable to nocturnal predators. Such a hypothesis is consistent with the predominantly behavioral antipredator defenses displayed by the most active, but structurally vulnerable, pulmonates tested in this study ( $P$. acuta and P. planorbis) (e.g., Turner et al., 1999; but see DeWitt et al., 2000). $B$. leachii instead may resort to behavioral responses when active (e.g., by quickly retreating into the shell and shutting the operculum: Brönmark and Malmqvist, 1986) and to structural defenses when inactive (i.e., thick shell with operculum closed shut). The overall higher degree of activity, including at night (Fig. 2), exhibited by the otherwise structurally vulnerable $P$. acuta supports the hypothesis that this species strongly relies on behavioral antipredator defenses that require a certain degree of constant alertedness (e.g., crawling out of water, detaching from substratum, etc.: Turner et al., 1999). However, studies specifically targeting a link between activity and antipredator defense are needed to test this hypothesis.

Their inherent diurnal habits may make the six species tested in this study particularly effective at shortcircuiting energy and nutrients within the benthic component of littoral food webs, while maintaining low standing crops of periphyton. In fact, periphyton heavily grazed upon by snails often responds with increased productivity despite sustained low standing crop (Bourassa and Cattaneo, 1998; Muñoz et al., 2000). Nutrient uptake by algae is higher in the light, with some leaking back into the water near dusk (Overbeck, 1962; Soeder, 1965). The consequent sustained demand for nutrients would retain much of the latter within the benthic compartment of the littoral zone, preventing phytoplankton from developing and thus maintaining high water clarity in the littoral zone. Periphyton is also favored over macrophytes for nutrient uptake from the water column (e.g., Moeller et al., 1988), 
so that low periphyton biomass on macrophytes allows the latter to take full advantage of light and dissolved nutrients (Jones et al., 2000; Lombardo, 2005), allowing for a healthy, dense growth. Healthy macrophytes in well-lit, nutrient-rich waters also may further inhibit phytoplankton by producing more anti-algal allelochemicals (Gross, 2003). Predominantly diurnal grazing on periphyton may then translate into higher periphyton and macrophyte productivity, as autotrophs would be stimulated at the time of maximum photosynthetic rate (thus accelerating nutrient recycling within the littoral, benthic community), but into higher biomass only of unpalatable macrophytes. Because macrophytes are central to sustained water transparency in shallow-water, nutrient-rich habitats (e.g., Scheffer, 1998), heavy periphyton grazers with diurnal habits may effectively contribute to stabilize a macrophyte-dominated clear-water state even in otherwise phytoplankton-favoring nutrient-rich habitats. Physid commonness, high effectiveness as periphyton grazers (Jones et al., 1999; Lombardo, 2001), and highly active (feeding) behavior (this study), suggest that $P$. acuta may indeed play a keystone role in macrophytebased littoral food webs, as suggested by Lombardo (2001), and more so than other snail species with similar diurnal habits.

Other aspects remain untested. For example, we tested individual snails in isolation, and the influence of neighboring conspecifics (or allospecifics) on individual behavior remains unknown. This aspect may be particularly important for $P$. acuta, given its more flexible habits and quicker response to stimuli (Figs. 2-4) coupled with its typical occurrence in crowded populations and communities (Jokinen, 1987; Lombardo, 2005; authors' personal observations). Increases in activity following external stimuli (Fig. 4) suggest that $P$. acuta may be more active in multiple-individual communities than in isolation. If $P$. acuta in naturally crowded communities is indeed more behaviorally flexible and responds more quickly to stimuli than in isolation, its potential role as a keystone grazer in littoral communities and its anti-predator behavioral "sensitivity" may be even more pronounced than our investigation suggests. Also, the activity scale used in this investigation (Table 2) was "standardized" across species, so that the effective degree of activity-related grazing pressure for the highly mobile, "fast" P. acuta may be even higher than this study suggests. In order to fully assess the ecological role of $P$. acuta and other freshwater snails in natural communities, we advocate more studies addressing the potential influence of temporal aspects on snail behavior and ecological characteristics.

Acknowledgements. We thank Ms. Daniela Giustini (UoLA) and Ms. Berit Kramer (NIVA, Oslo, Norway) for assistance with some hard-to-obtain literature, and Ms. Teresa Mastracci (UoLA) for assistance with lab and field activities. Criticism from two anonymous reviewers greatly improved the paper. We also thank Mr. Fabrizio F. Lombardo and Mrs. Teresa M. Abbà Lombardo for providing the experimental locale in Rome.

\section{References}

Anderson R., 2003. Physella (Costatella) acuta Draparnaud in Britain and Ireland - Its taxonomy, origins and relationships to other introduced Physidae. J. Conchol., 38, 7-21.

Bank R.A., 2007. Fauna Europaea: Mollusca: GastropodaFauna Europaea version 1.3, available at http://www. faunaeur.org, last visited 2nd January 2010.

Batschelet E., 1965. Statistical Methods for the Analysis of Problems in Animal Orientation and Certain Biological Rhythms, American Institute of Biological Sciences, Washington, DC.

Batschelet E., 1981. Circular Statistics in Biology, Academic Press, New York.

Beeston D.E. and Morgan E., 1977. The locomotor activity rhythm of a tropical freshwater prosobranch. J. Moll. Stud., 43, 453-454.

Berg K. and Ockelmann K.W., 1959. The respiration of freshwater snails. J. Exp. Biol., 36, 690-708.

Bourassa N. and Cattaneo A., 1998. Control of periphyton biomass in Laurentian streams (Québec). J. N. Am. Benthol. Soc., 17, 420-429.

Brönmark C. and Malmqvist B., 1986. Interactions between the leech Glossiphonia complanata and its gastropod prey. Oecologia, 69, 268-276.

Brönmark C. and Weisner S.E.B., 1992. Indirect effects of fish community structure on submerged vegetation in shallow, eutrophic lakes: an alternative mechanism. Hydrobiologia, 243/244, 293-301.

Brown K.M., 1982. Resource overlap and competition in pond snails: an experimental analysis. Ecology, 63, 412-422.

Brown K.M., 2001. Mollusca: Gastropoda. In: Thorp J.H. III and Covich A.P. (eds.), Ecology and Classification of North American Freshwater Invertebrates, 2nd edn., Academic Press, San Diego, 297-329.

Burgmer T., Hillebrand H. and Pfenninger M., 2007. Effects of climate-driven temperature changes on the diversity of freshwater macroinvertebrates. Oecologia, 151, 93-103.

Chaudry M. and Morgan E., 1987. Factors affecting the growth and fecundity of Bulinus tropicus. J. Moll. Stud., 53, 52-61.

Cianfanelli S., Lori E. and Bodon M., 2007. Non-indigenous freshwater molluses and their distribution in Italy. In: Gherardi F. (ed.), Biological Invaders in Inland Waters: Profiles, Distribution, and Threats, Springer, Dordrecht, 103-121.

Costil K., 1994. Influence of temperature on survival and growth of two freshwater planorbid species, Planorbarius corneus (L.) and Planorbis planorbis (L.). J. Moll. Stud., 60, 223-235.

Costil K. and Clement B., 1996. Relationship between freshwater gastropods and plant communities reflecting various trophic levels. Hydrobiologia, 321, 7-16.

Crowl T.A. and Covich A.P., 1990. Predator-induced life-history shifts in a freshwater snail. Science, 247, 949-951.

DeWitt T.J., Robinson B.W. and Wilson D.S., 2000. Functional diversity among predators of a freshwater snail imposes an adaptive trade-off for shell morphology. Evol. Ecol. Res., 2, 129-148.

Dillon R.T. Jr., 2000. The Ecology of Freshwater Molluscs, Cambridge University Press, Cambridge.

Dillon R.T. Jr., Wethington A.R., Rhett J.M. and Smith T.P., 2002. Populations of the European freshwater pulmonate 
Physa acuta are not reproductively isolated from American Physa heterostropha or Physa integra. Invert. Biol., 121, 226-234.

Ferreri D., 1995. Molluschi, irudinei, e turbellaria tricladi delle acque dolci della Provincia di Lecce. Thal. Salent., 21, 29-49.

Gaino E., Cianficconi F., Corallini Sorcetti C., Lancioni T., Todini B., Rebora M., Chiappafreddo U., Bicchierai M.C. and Spinelli G., 2001. Lago di Piediluco: Monitoraggio della Fauna del Canneto (Poriferi e Macroinvertebrati), 19992000. Unpublished report, Department of Animal Biology and Ecology, University of Perugia.

García-Berthou E., Boix D. and Clavero M., 2007. Nonindigenous animal species naturalized in Iberian inland waters. In: Gherardi F. (ed.), Biological Invaders in Inland Waters: Profiles, Distribution, and Threats, Springer, Dordrecht, 123-140.

Girod A., Bianchi I. and Mariani M., 1980. Guide per il Riconoscimento delle Specie Animali delle Acque Interne Italiane. 7. Gasteropodi, 1. (Pulmonata; Prosobranchia: Neritidae, Viviparidae, Bithyniidae, Valvatidae), CNR Publication \# AQ/1/44, Consiglio Nazionale delle Ricerche, Verona.

Gotelli N.J. and Ellison A.M., 2004. A Primer of Ecological Statistics, Sinauer, Sunderland.

Gross E.M., 2003. Differential response of tellimagrandin II and total bioactive hydrolysable tannins in an aquatic angiosperm to changes in light and nitrogen. Oikos, 103, 497-504.

Hodasi J.K.M., 1976. The effects of low temperature on Lymnaea truncatula. Zeits. Parasitenk., 48, 281-286.

Hotelling H., 1931. The generalization of Student's ratio. Ann. Math. Statist., 2, 360-378.

Hourdin P., Vignoles P., Dreyfuss G. and Rondelaud D., 2006. Galba truncatula (Gastropoda, Lymnaeida): effects of daily water level variations on the ecology and ethology of populations living upstream from a dam. Ann. Limnol. - Int. J. Lim., 42, 173-180.

Hurlbert S.H., 1984. Pseudoreplication and the design of ecological field experiments. Ecol. Monogr., 54, 187-211.

Jokinen E.H., 1987. Structure of freshwater snail communities: species-area relationships and incidence categories. Am. Malacol. Bull., 5, 9-19.

Jones J.I., Young J.O., Haynes G.M., Moss B., Eaton J.W. and Hardwick K.J., 1999. Do submerged aquatic plants influence their periphyton to enhance the growth and reproduction of invertebrate mutualists? Oecologia, 120, 463-474.

Jones J.I., Eaton J.W. and Hardwick K., 2000. The influence of periphyton on boundary layer conditions: a $\mathrm{pH}$ microelectrode investigation. Aquat. Bot., 67, 191-206.

Kabat A.K. and Hershler R., 1993. The Prosobranch Snail Family Hydrobiidae (Gastropoda: Rissoidea): Review of Classification and Supraspecific Taxa, Smithsonian Contributions to Zoology \#547, Smithsonian Institution Press, Washington.

Kelly P.M. and Cory J.S., 1987. Operculum closing as a defence against predatory leeches in four British freshwater prosobranch snails. Hydrobiologia, 144, 121-124.

Kesler D.H. and Munns W.R. Jr., 1989. Predation by Belostoma flumineum (Hemiptera): an important cause of mortality in freshwater snails. J. N. Am. Benthol. Soc., 8, 342-350.
Lakowitz T., Brönmark C. and Nyström P., 2008. Tuning in to multiple predators: conflicting demands for shell morphology in a freshwater snail. Freshw. Biol., 53, 2184-2191.

Lombardo P., 1997. Predation by Enallagma nymphs (Odonata, Zygoptera) under different conditions of spatial heterogeneity. Hydrobiologia, 356, 1-9.

Lombardo P., 2001. Effects of freshwater gastropods on epiphyton, macrophytes, and water transparency under meso- to eutrophic conditions, Ph.D. Dissertation, Kent State University, Kent.

Lombardo P., 2005. Applicability of littoral food-web biomanipulation for lake management purposes: snails, macrophytes, and water transparency in northeast Ohio shallow lakes. Lake Reserv. Manage., 21, 186-202.

Lombardo P. and Cooke G.D., 2002. Consumption and preference of selected food types by two freshwater gastropod species. Arch. Hydrobiol., 155, 667-685.

Lombardo P. and Cooke G.D., 2004. Resource use and partitioning by two co-occurring freshwater gastropod species. Arch. Hydrobiol., 159, 229-251.

Lowe R.L. and Hunter R.D., 1988. Effects of grazing by Physa integra on periphyton community structure. J. N. Am. Benthol. Soc., 7, 29-36.

Macan T.T., 1977. The influence of predation on the composition of fresh-water animal communities. Biol. Rev., 52, $45-70$.

Mastrantuono L. and Mancinelli T., 2005. Littoral invertebrates associated with aquatic plants and bioassessment of ecological status in Lake Bracciano (Central Italy). J. Limnol., 64, 43-53.

McDonald S., 1973. Activity patterns of Lymnaea stagnalis (L.) in relation to temperature conditions: a preliminary study. Malacologia, 14, 395-396.

Moeller R.E., Burkholder J.M. and Wetzel R.G., 1988. Significance of sedimentary phosphorus to a submersed freshwater macrophyte (Najas flexilis) and its algal epiphytes. Aquat. Bot., 32, 261-281.

Morgan E. and Last V., 1982. The behavior of Bulinus africanus: a circadian profile. Anim. Behav., 30, 557-567.

Mouthon J. and Daufresne M., 2008. Population dynamics and life cycle of Pisidium amnicum (Müller) (Bivalvia: Sphaeriidae) and Valvata piscinalis (Müller) (Gastropoda: Prosobranchia) in the Saône River, a nine-year study. Ann. Limnol. - Int. J. Lim., 44, 241-251.

Muñoz I., Real M., Guasch H., Navarro E. and Sabater S., 2000. Resource limitation by freshwater snail (Stagnicola vulnerata) grazing pressure: an experimental study. Arch. Hydrobiol., 148, 517-532.

Overbeck J., 1962. Untersuchungen zum Phosphathaushalt von Grünalgen. III. Das Verhalten der Zellfraktionen von Scenedesmus quadricauda (Turp.) Bréb. im Tagescyclus unter verschiedenen Belichtungsbedingungen und bei verschidenen Phosphatverbindungen. Arch. Mikrobiol., 41, 11-26.

Peckarsky B.L. and Cowan C.A., 1995. Microhabitat and activity periodicity of predatory stoneflies and their mayfly prey in a western Colorado stream. Oikos, 74, 513-521.

Perrin N., 1986. Les paramètres du cycle vital de Physa acuta (Gastropoda, Mollusca) en milieu expérimental. Rev. Suisse Zool., 93, 725-736.

Pianka E.R., 1976. Competition and niche theory. In: May R.M. (ed.), Theoretical Ecology, Principles and Applications, Blackwell Scientific Publications, Oxford, 114-141. 
Pimentel-Souza F., Schall V.T., Lautner R. Jr., Barbosa N.D.C., Schettino M. and Fernandes N., 1984. Behavior of Biomphalaria glabrata (Gastropoda: Pulmonata) under different lighting conditions. Can. J. Zool., 62, 2328-2334.

Rotenberg L., Jurberg P. and Pieri O.S., 1989. Relationship between light conditions and behavior of the freshwater snail Biomphalaria glabrata (Say). Hydrobiologia, 174, 111-116.

Russell-Hunter W., 1961. Life cycles of four freshwater snails in limited populations in Loch Lomond with a discussion of infraspecific variation. Proc. Zool. Soc. London, 137, 135-171.

Scheffer M., 1998. Ecology of Shallow Lakes, reprinted with corrections in 2004, Kluwer Academic Publishers, Dordrecht.

Soeder C.J., 1965. Some aspects of phytoplankton growth and activity. Mem. Ist. Ital. Idrobiol., 18, Suppl., 47-59.

Ter Maat A., Zonneveld C., de Visser J.A.G.M., Jansen R.F., Montagne-Wajer K. and Koene J.M., 2007. Food intake, growth, and reproduction as affected by day length and food availability in the pond snail Lymnaea stagnalis. Am. Malacol. Bull., 23, 113-120.
Tomba A.M., Keller T.A. and Moore P.A., 2001. Foraging in complex odor landscapes: chemical orientation strategies during stimulation by conflicting chemical cues. J. N. Am. Benthol. Soc., 20, 211-222.

Tripet F. and Perrin N., 1994. Size-dependent predation by Dugesia lugubris (Turbellaria) on Physa acuta (Gastropoda): experiments and model. Funct. Ecol., 8, 458-463.

Turner A.W., Fetterolf S.A. and Bernot R.J., 1999. Predator identity and consumer behavior: differential effects of fish and crayfish on the habitat use of a freshwater snail. Oecologia, 118, 242-247.

Underwood A.J., 1997. Experiments in Ecology: Their Logical Design and Interpretation Using Analysis of Variance, Cambridge University Press, Cambridge.

Wojdak J.M. and Mittelbach G.G., 2007. Consequences of niche overlap for ecosystem functioning: an experimental test with pond grazers. Ecology, 88, 2072-2083.

Zar J.H., 1998. Biostatistical Analysis, 4th edn., Prentice Hall, Upper Saddle Creek. 